\title{
Prevalence of Subclinical Coronary Artery Disease in Middle-Aged, Male Marathon Runners Detected by Cardiac CT
}

\section{Prävalenz subklinischer koronarer Herzkrankheit bei männlichen Marathonläufern mittleren Alters: Detektion mittels koronarer CT-Angiografie}

Authors

Affiliations
I. Tsiflikas' ${ }^{1}$, C. Thomas ${ }^{1}$, C. Fallmann², C. Schabel ${ }^{1}$, S. Mangold ${ }^{1}$, D. Ketelsen ${ }^{1}$, C. D. Claussen ${ }^{1}$, D. Axmann ${ }^{3}$, S. Schroeder ${ }^{4}$, C. Burgstahler ${ }^{3}$

\author{
Diagnostic and Interventional Radiology, University Hospital of Tuebingen, Germany \\ 2 Sports Medicine, University Hospital of Tuebingen, Germany \\ 3 Center of Dentistry Oral Medicine and Maxillofacial Surgery, University Hospital of Tuebingen, Germany \\ ${ }^{4}$ Internal Medicine, Klinikum am Eichert, Goeppingen, Germany
}

\author{
Key words \\ - cardiac \\ - CT \\ - CT angiography
}

$\begin{array}{ll}\text { received } & 9.9 .2014 \\ \text { accepted } & 18.1 .2015\end{array}$

Bibliography

Dol http://dx.doi.org/

10.1055/s-0034-1399221

Published online: 1.4.2015

Fortschr Röntgenstr 2015; 187:

561-568 @ Georg Thieme

Verlag KG Stuttgart · New York .

ISSN 1438-9029

\section{Correspondence \\ Ilias Tsiflikas}

Diagnostic and Interventional Radiology, University Hospital of Tuebingen

Hoppe-Seyler-Str. 3

72076 Tuebingen

Germany

Tel.: +4970712986677

Fax: +497071295845

ilias.tsiflikas@med.uni-

tuebingen.de

\section{Zusammenfassung \\ $\nabla$}

Ziel: Ziel der Studie war die Evaluierung der Prävalenz der KHK bei männlichen Marathonläufern mittleren Alters mittels Dual Source cCTA (DSCTA). Material und Methoden: 50 Marathonläufer (52,7 \pm 5 ,9 Jahre) wurden zusätzlich zur sportmedizinischen Routinediagnostik mittels DSCTA einschließlich Calcium-Scoring (CS) untersucht. Das CS wurde bei allen Personen im high-pitchModus (hpDSCTA), die CTA bei 21 Personen im hpDSCTA und 29 Personen im sequentiellen „step-and-shot“-Modus (sDSCTA) durchgeführt. Die effektive Dosis (ED) wurde für beide Scanverfahren bestimmt. Der Risikofaktor für koronare Ereignisse wurde basierend auf Standardrisikofaktoren mittels des PROCAM-Scores berechnet. Der Koronarstatus wurde wie folgt klassifiziert: 1. keine $\mathrm{KHK}(\mathrm{CS}=0$, keine Koronarplaques), 2. milde Koronarsklerose (CS $>0$, Stenose $<50 \%$ ), 3. moderate Koronarsklerose ( $\mathrm{CS}>0$, Stenose $>50 \%$ ) 4. signifikante KHK (CS >0, Stenose $>75 \%$ ). Ergebnisse: Der mediane PROCAM-Score betrug $1,85 \pm 1,56 \% .26$ von 50 Marathonläufern hatten keine KHK. 1 Person hatte eine signifikante KHK, 3 Personen eine moderate sowie 20 eine milde Koronarsklerose. Die Laufband-Ergometrie konnte bei keinem Sportler Koronarischämien nachweisen. Als Faktoren für ein erhöhtes KHK-Risiko konnten Alter, Blutdruck, persönliche Mindestzeit, familiäre Anamnese und der PROCAM-Score identifiziert werden. Die mediane ED für die DSCTA lag bei $1,259 \pm 0,542 \mathrm{mSv}$. Bei der hpDSCTA war die ED im Vergleich zur sDSCTA signifikant niedriger $(0,762$ vs. $1,618 \mathrm{mSv}, \mathrm{p}<0,0001)$.

Schlussfolgerung: Bei fast $50 \%$ der asymptomatischen Marathonläufer über 45 Jahren kann mittels cCTA eine Koronarsklerose nachgewiesen werden. Bei 24\% dieser Probanden waren die Plaques in den proximalen Abschnitten der Koronararterien lokalisiert. Tatsächlich leidet jedoch nur ein kleiner Anteil dieser Personen an einer obstruktiven KHK.

\section{Abstract \\ $\nabla$}

Purpose: To evaluate the prevalence of coronary artery disease (CAD) in middle-aged, male marathon runners using coronary dual source $\mathrm{CT}$ angiography (DSCTA).

Materials and Methods: 50 male marathon runners older than 45 years (mean age: 52.7, standard deviation: 5.9 years, range: 45 to 67 years) received DSCTA including calcium scoring (CS) in addition to standard pre-participation screening. Based on standard risk factors, the risk for coronary events was calculated using the PROCAM score. Coronary status was defined using the following system: 1 . absence of CAD (CS zero, no coronary plaques) 2 . mild coronary atherosclerosis ( $C S>0$, coronary plaques with luminal narrowing $<50 \%$ ), 3. moderate coronary atherosclerosis (CS $>0$, luminal narrowing $>50 \%$ ), 4 . significant $C A D$ (CS $>0$, luminal narrowing $>75 \%$ ).

Results: The mean PROCAM score was $1.85 \%$ (standard deviation $=1.56$, range 0.39 to $8.47 \%$ ). 26/50 marathon runners had no atherosclerosis. 1 of the remaining 24 participants had significant CAD, 3 had moderate coronary atherosclerosis and 20 had mild coronary atherosclerosis. Treadmill exercise testing was unremarkable in terms of myocardial ischemia in all participants. Age, systolic blood pressure, personal minimum time, family history of cardiovascular disease and PROCAM score were factors associated with an increased risk for coronary atherosclerosis.

Conclusion: Coronary atherosclerosis can be detected in almost $50 \%$ of male marathon runners aged older than 45 years. In $24 \%$ of the participants plaques were located in the proximal coronary system. However, only a minority of these persons have obstructive CAD. As expected, treadmill exercise testing failed to detect these persons that possibly have a higher risk for coronary events. 
Die Laufband-Ergometrie kann wie erwartet diese Risikopersonen für koronare Ereignisse nicht erkennen.

Kernaussagen:

- Koronarsklerose bei 50\% männlicher Marathonläufer > 45 Jahre

- Nur ein kleiner Teil dieser Personen leidet an einer obstruktiven KHK

- Auf dem Laufbandergometer können diese Risikopersonen nicht erkannt werden

- Kardio-CT mögliche Hilfe bei der Detektion der Athleten mit erhöhtem koronaren Risiko, insbesondere bei familiärem Risikoprofil
Key points:

- Coronary atherosclerosis can be detected in $~ 50 \%$ of male marathon runners $>45$ years

- Only a minority of these persons have obstructive CAD

- Treadmill exercise testing failed to detect these persons

- Cardiac CT might help to identify athletes with elevated risk for coronary events, especially in persons with a family history of coronary artery disease

Citation Format:

- Tsiflikas I, Thomas C, Fallmann C et al. Prevalence of Subclinical Coronary Artery Disease in Middle-Aged, Male Marathon Runners Detected by Cardiac CT. Fortschr Röntgenstr 2015; 187 : 561-568

\section{Introduction \\ $\nabla$}

Regular physical exercise is an inherent part of the prevention of cardiovascular disease [1]. On the other hand, intensive physical exertion raises the risk for fatal cardiac events in persons with underlying cardiovascular diseases [2]. To reduce the risk for (fatal) cardiovascular events, pre-participation screening is recommended before starting physical activity or performing competitive sports. However, the concept of pre-participation screening differs between the American Heart Association (AHA) and the European Society of Cardiology (ESC). While the AHA only recommends standard history and physical examination in younger athletes [3], the ESC guidelines consider the evaluation of a resting ECG to be an integral part in terms of pre-participation screening [4]. According to the AHA, medically supervised exercise testing should be performed only in competitive male athletes older than 40 years (or women older than 55 years) and with at least two additional cardiovascular risk factors or in persons with a markedly abnormal single risk factor [3]. A comparable approach has been published by the sections of exercise physiology and sports cardiology of the European Association of Cardiovascular Prevention and Rehabilitation. Maximal exercise testing is restricted to high-risk persons with at least moderate intensity activity [5]. While hypertrophic cardiomyopathy is the most common cause for sudden cardiac death in younger athletes [6], fatal cardiovascular events in athletes older than 35 years are typically the result of coronary artery disease (CAD) [7] in accordance with the general population, since atherosclerosis is a disease of aging beginning in the youth $[8,9]$. Unfortunately the diagnostic accuracy of exercise testing to predict coronary events is low [10] as it depends on the pre-test probability with a high rate of false-negative tests in patients with a high pre-test probability and a high rate of false-positive tests in patients with a low pretest probability [11]. In contrast, cardiac computed tomography angiography (CTA) is characterized by high diagnostic accuracy to detect or rule out coronary artery disease noninvasively [12, 13]. Based on these assumptions, there might be the need for extended cardiovascular pre-participation screening using CTA.

\section{Materials and methods \\ $\nabla$}

\section{Marathon runners}

The local ethics committee and the federal authority for radiation protection agreed to this study. 50 male marathon runners recruited by an advertisement in local newspapers and aged $>45$ years were included in the study. They received CTA in addition to stand- ard pre-participation screening. All participants gave their informed consent to take part in this study. The investigation was conducted in accordance with the Declaration of Helsinki.

\section{Pre-participation screening}

To exclude cardiovascular and other relevant diseases, each participant underwent a physical examination, rest ECG and color Doppler echocardiography. The resting heart rate and blood pressure at rest were determined. In addition, all athletes underwent treadmill stress tests to evaluate maximal oxygen uptake (VO2 max). Training experience, weekly training volume averaged over the preceding 6 months, number of completed marathons and personal minimum time were recorded in each participant.

Exclusion criteria were known CAD, allergic reaction to iodinated contrast media, renal insufficiency (glomerular filtration rate $<60 \mathrm{ml} / \mathrm{min}$ ), hyperthyroidism (basal TSH $<0.03 \mathrm{mU} / \mathrm{L}$ in combination with elevation of the peripheral thyroid hormones).

\section{Cardiovascular risk factors}

To assess the cardiovascular risk profile, standard blood parameters (total cholesterol, LDL cholesterol, HDL cholesterol, triglyceride levels, fasting glucose) were determined in each participant after a fasting period of at least $8 \mathrm{~h}$. Additional risk factors like family history of cardiovascular disease (defined as confirmed coronary artery disease or peripheral artery disease in a first degree relative), diabetes mellitus, smoking or hypertension were evaluated on the basis of the medical history. The PROCAM (Prospective Cardiovascular Munster study) score [14] was calculated to characterize the individual's global cardiovascular risk more accurately.

\section{Dual source computed tomography}

All examinations were performed with a second-generation dual source CT system (Somatom Definition Flash, Siemens Healthcare, Forchheim, Germany). The participants were placed on the examination table in a supine position. After planning the scan range, an initial prospective ECG-triggered, high-pitch non-contrast DSCT scan was performed for the assessment of coronary calcium using the following parameters: Collimation $2 \times 64 \times 0.6 \mathrm{~mm}$ with a $\mathrm{z}$-flying focal spot, gantry rotation time $280 \mathrm{~ms}$, pitch 3.4 , tube current $70 \mathrm{~mA}$ per rotation with automatic tube current modulation, and tube voltage $120 \mathrm{kV}$.

Afterwards, the circulation time was determined using a test bolus with $10 \mathrm{ml}$ of iodinated contrast media (370 mg iodine/ml, Ultravist 370, Bayer Healthcare, Germany) at a flow setting of $6.0 \mathrm{ml} / \mathrm{s}$ and a $20 \mathrm{ml}$ saline chaser with a dual-head injector (CT Stellant, Medrad, Indianola, Pennsylvania). 
Depending on heart rate, participants were scanned with one of the following scan protocols: In participants with a heart rate $<60 /$ min a prospective triggered, high-pitch DSCTA, and in participants with a heart rate $>60 /$ min a prospective triggered, sequential DSCTA ("step-and-shoot") was performed. In high-pitch DSCTA the tube current was set to $350 \mathrm{~mA} /$ rotation as a reference setting for automated tube current modulation, tube voltage $100 \mathrm{kV}$, collimation $2 \times 64 \times 0.6 \mathrm{~mm}$ with a $\mathrm{z}$-flying focal spot, gantry rotation time $280 \mathrm{~ms}$, pitch 3.4 . In prospective triggered, sequential DSCTA the following parameters were used: tube current $350 \mathrm{mAs}$, tube voltage $100 \mathrm{kV}$, collimation $2 \times 64 \times 0.6 \mathrm{~mm}$ with a z-flying focal spot, gantry rotation time $280 \mathrm{~ms}$, scan range of $13.5 \mathrm{~cm}$ (four blocks of sequential detector coverage).

In both scan techniques $60 \%$ of the RR-interval was set to trigger the scan.

$70 \mathrm{ml}$ of contrast media and a saline chaser were applied at a flow setting of $6.0 \mathrm{ml} / \mathrm{s}$.

For calcium scoring (CS) overlapping images with 3-mm effective slice thickness and a medium sharp non-edge-enhancing convolution kernel (B35f) were reconstructed. CTA images were reconstructed using a soft B26 f kernel at a slice thickness of $0.75 \mathrm{~mm}$ and an increment of $0.4 \mathrm{~mm}$.

Evaluation of the coronary artery angiography was performed in consensus by two experienced radiologists. Thin slab maximumintensity projections and curved multiplanar reformations were used. For rating of image quality and stenosis detection, a modified 15-segment model of the American Heart Association was used: right coronary artery (RCA): 1 : proximal, 2 : middle, 3 : distal, and 4: combined posterior descending and posterolateral branches; left main stem (LM): 5; left anterior descending artery (LAD): 6: proximal, 7: middle, 8: distal, 9: first diagonal, and 10: second diagonal; left circumflex artery (LCX): 11: proximal, 12: first marginal branch, and 13: distal, 14: left posterolateral branch, and 15: left posterior descending.

\section{Extent of coronary artery disease}

The total calcium burden was graded according to Rumberger et al. [15] in the following categories: Agatston score 0 (no evidence of coronary calcium), 1 - 10 (minimal evidence of coronary calcium), 10 - 100 (mild evidence of coronary calcium), 100 - 400 (moderate evidence of coronary calcium) and $>400$ (extensive evidence of coronary calcium).

Furthermore, we defined CAD adapted to this score using the following system including calcium score and evaluation of coronary stenosis by CTA: 1 . absence of CAD (CS zero, no coronary plaques), 2. mild $\mathrm{CAD}(\mathrm{CS}>0$, coronary plaques with luminal narrowing $<50 \%)$, 3. moderate $\mathrm{CAD}(\mathrm{CS}>0$, luminal narrowing $>50 \%$ ), 4. significant CAD (CS >0, luminal narrowing $>75 \%$ ).

\section{Statistical analysis}

Statistical analysis was performed with computer software (JMP version 10, SAS Institute, Cary, NC). Continuous, normally distributed variables are summarized as the mean (standard deviation SD) [range], and, if necessary, the median was added. Differences between the two groups were tested by student's t-test in case of normal distribution (t-statistic). Otherwise, the Wilcoxon test was performed (Chi ${ }^{2}$-statistic).

Differences between two or more than two groups were performed by Pearson's chi²-test. Odds ratios were calculated from contingency tables. A p-value of less than 0.05 was regarded as statistically significant.

\section{Results}

\section{$\nabla$}

\section{Patient characteristics}

The mean age of the participants was 52.7 years (SD 5.9), ranging from 45 to 67 years. The mean PROCAM score was 1.9\% (range $0.39 \%$ to $8.47 \%$, SD $1.6 \%$ ). The number of completed marathons ranged from 1 to 72 (median 7, mean 13.8, SD 16.2) with a personal minimum time between $2: 33 \mathrm{~h}$ and $4: 30 \mathrm{~h}$ (median $3: 28 \mathrm{~h}$, mean 3:28 h, SD 0:27 h). 43 of the participants were active marathon runners with the last completed marathon within the last 12 months. From the remaining 7 participants, 3 had finished their last marathon in the last 24 months, 2 in the last 36 months and only 2 participants were sedentary with the last marathon having been run more than 5 years ago. No athlete was suffering from diabetes. Hypercholesterolemia (defined as $>160 \mathrm{mg} / \mathrm{dl}$ or present medication with lipid lowering drugs) was present in 3 athletes. 4 participants had a history of hypertension (defined as the presence of antihypertensive medication). 17 (34\%) athletes were ex-smokers, 24 (48\%) had a family predisposition of CAD, 1 athlete was obese. Detailed data are given in $\bullet$ Table 1.

Beside one marathon runner that reported atypical chest discomfort during physical activity, all other persons were free of cardiovascular symptoms suspicious of coronary artery disease. Treadmill exercise testing was unremarkable in terms of myocardial ischemia in all participants.

\section{Coronary computed tomography and extent of coronary artery disease}

All coronary scans were of diagnostic quality. 26/50 (52\%) marathon runners had no atherosclerosis. 1 of the remaining 24 participants had significant CAD, 3 had moderate CAD and 20 had mild coronary artery disease. The distribution of CAD within the athletes according to the time since the last finished marathon was as follows: 23 of 43 athletes who had finished their last marathon within the last 12 months had no evidence of CAD, 18 athletes had mild CAD and 2 athletes had moderate CAD. The athlete with significant CAD had finished his last marathon within the last 24 months, one of the other two athletes from this group had no evidence of CAD and the other one had mild CAD. In the group of athletes who had finished their last marathon within the last 36 months, one of two had no evidence of CAD and the other one had moderate CAD. Among the sedentary athletes, one had no CAD and one had mild CAD. Age, systolic blood pressure, personal minimum time and PROCAM score differed between athletes with and without coronary atherosclerosis ( $\bullet$ Table 1 ).

The mean calcium score was 43.5 (range 0 - 745.8, median 0 , SD 121.0). 26/50 athletes had no coronary calcium, 9 athletes had a calcium score up to 10, 9 athletes had a calcium score between 10 and 100, and 4 athletes had a calcium score between 100 and 400 and 1 athlete had a calcium score $>400$ ( $\bullet$ Fig. 1 ). The correlation between age and calcium score $\left(r^{2}=0.18, p=0.002\right)$ as well as PROCAM score and calcium score $\left(\mathrm{r}^{2}=0.22, \mathrm{p}=0.0005\right)$ was only moderate ( Fig. 2,3 ). The oldest athlete without coronary lesions was 67 years old, and the youngest athlete with coronary atherosclerosis was 45 years old.

In total 34 coronary lesions were detected ( 9 non-calcified, 8 mixed, 17 calcified). In one person an additional stress MRI was recommended to exclude myocardial ischemia due to moderate coronary stenosis. The person with atypical chest pain showed high-grade stenosis in the left anterior descending artery ( $\bullet$ Fig. 4). Invasive angiography could confirm high-grade steno- 
Table 1 Patient characteristics, mean (SD), [range].

Tab. 1 Patientencharakteristika, Mittelwert (SD), [Spannbreite].

\begin{tabular}{|c|c|c|c|c|c|c|}
\hline & $\begin{array}{l}\text { study population } \\
(n=50)\end{array}$ & $\begin{array}{l}\text { no CAD } \\
(n=26)\end{array}$ & $\begin{array}{l}\text { CAD } \\
(n=24)\end{array}$ & difference & $\begin{array}{l}\text { t-value or } \\
\text { Chi }^{2}\end{array}$ & $\begin{array}{l}\text { p-value group } 1 \\
\text { vs. group } 2\end{array}$ \\
\hline age [years] & $\begin{array}{l}52.6(5.9) \\
{[45-67]}\end{array}$ & $\begin{array}{l}50.9(5.7) \\
{[45-67]}\end{array}$ & $\begin{array}{l}54.5(5.5) \\
{[45-67]}\end{array}$ & $\begin{array}{l}3.62 \\
{[0.42-6.81]}\end{array}$ & $6.409 \#^{1}$ & $p=0.01$ \\
\hline weight [kg] & $\begin{array}{l}76.6(9.59) \\
{[54-105]}\end{array}$ & $\begin{array}{l}75.4(10.2) \\
{[54-101]}\end{array}$ & $\begin{array}{l}77.8(8.8) \\
{[64-105]}\end{array}$ & $\begin{array}{l}2.3 \\
{[-3.03-7.80]}\end{array}$ & 0.88 & $p=0.38$ \\
\hline height [cm] & $\begin{array}{l}180(6) \\
{[170-195]}\end{array}$ & $\begin{array}{l}180(7) \\
{[170-195]}\end{array}$ & $\begin{array}{l}180(4) \\
{[171-186]}\end{array}$ & $\begin{array}{l}-0.27 \\
{[-3.4-2.87]}\end{array}$ & -0.17 & $p=0.87$ \\
\hline systolic blood pressure [mmHg] & $\begin{array}{l}131(15) \\
{[105-165]}\end{array}$ & $\begin{array}{l}125(13) \\
{[105-150]}\end{array}$ & $\begin{array}{l}137(15) \\
{[105-165]}\end{array}$ & $\begin{array}{l}12.28 \\
{[4.31-20.25]}\end{array}$ & 3.10 & $p=0.003$ \\
\hline $\begin{array}{l}\text { diastolic blood pressure } \\
{[\mathrm{mmHg}]}\end{array}$ & $\begin{array}{l}83(8) \\
{[65-100]}\end{array}$ & $\begin{array}{l}81(7) \\
{[65-90]}\end{array}$ & $\begin{array}{l}85(8) \\
{[70-100]}\end{array}$ & $\begin{array}{l}3.64 \\
{[-0.71-7.98]}\end{array}$ & 1.69 & $p=0.01$ \\
\hline BMI $\left[\mathrm{kg} / \mathrm{m}^{2}\right]$ & $\begin{array}{l}23.5(2.5) \\
{[18.7-33.1]}\end{array}$ & $\begin{array}{l}23.1(2.5) \\
{[18.7-26.6]}\end{array}$ & $\begin{array}{l}24.0(2.7) \\
{[20.4-33.1]}\end{array}$ & $\begin{array}{l}0.96 \\
{[-0.47-2.40]}\end{array}$ & 1.35 & $p=0.19$ \\
\hline $\mathrm{VO}_{2} \max [\mathrm{mL} / \mathrm{kg} / \mathrm{min}]$ & $\begin{array}{l}48.7(6.6) \\
{[37-63]}\end{array}$ & $\begin{array}{l}49.8(6.8) \\
{[37-63]}\end{array}$ & $\begin{array}{l}47.3(6.3) \\
{[38-59]}\end{array}$ & $\begin{array}{l}-2.54 \\
{[-6.31-1.23]}\end{array}$ & -1.36 & $p=0.1813$ \\
\hline $\begin{array}{l}\text { number of completed mara- } \\
\text { thons }\end{array}$ & $\begin{array}{l}13.8(16.2) \\
{[1-72]}\end{array}$ & $\begin{array}{l}12.0(13.3) \\
{[1-55]}\end{array}$ & $\begin{array}{l}15.6(18.9) \\
{[1-72]}\end{array}$ & $\begin{array}{l}3.57 \\
{[-6.10-13.23]}\end{array}$ & 0.75 & $p=0.46$ \\
\hline training volume [h/week] & $\begin{array}{l}5.0(1.8) \\
{[2-12]}\end{array}$ & $\begin{array}{l}5.0(2.1) \\
{[2-12]}\end{array}$ & $\begin{array}{l}4.9(1.4) \\
{[2-8]}\end{array}$ & $\begin{array}{l}-0.04 \\
{[-1.07-0.98]}\end{array}$ & -0.08 & $p=0.93$ \\
\hline training experience [years] & $\begin{array}{l}16.3(9.8) \\
{[3-50]}\end{array}$ & $\begin{array}{l}16.6(11.0) \\
{[3-50]}\end{array}$ & $\begin{array}{l}15.98 .6) \\
{[4-41]}\end{array}$ & $\begin{array}{l}-0.74 \\
{[-6.33-4.85]}\end{array}$ & -0.27 & $p=0.79$ \\
\hline personal minimum time [h:min] & $\begin{array}{l}3: 28(0: 27) \\
{[2: 33-4: 30]}\end{array}$ & $\begin{array}{l}3: 21(0: 26) \\
{[2: 33-4: 14]}\end{array}$ & $\begin{array}{l}3: 34(0: 27) \\
{[2: 50-4: 30]}\end{array}$ & $\begin{array}{l}0: 13 \\
{[0: 00: 07-0: 30: 03]}\end{array}$ & 2.09 & $p=0.048$ \\
\hline total cholesterol [mg/dl] & $\begin{array}{l}195(34) \\
{[122-271]}\end{array}$ & $\begin{array}{l}197(34) \\
{[152-271]}\end{array}$ & $\begin{array}{l}195(34) \\
{[122-260]}\end{array}$ & $\begin{array}{l}-2.15 \\
{[-21.55-17.25]}\end{array}$ & -0.22 & $p=0.82$ \\
\hline $\begin{array}{l}\text { LDL cholesterol } \\
{[\mathrm{mg} / \mathrm{dl}]}\end{array}$ & $\begin{array}{l}104(29) \\
{[47-166]}\end{array}$ & $\begin{array}{l}104(29) \\
{[47-166]}\end{array}$ & $\begin{array}{l}104(30) \\
{[66-148]}\end{array}$ & $\begin{array}{l}-0.46 \\
{[-17.34-16.45]}\end{array}$ & -0.06 & $p=0.96$ \\
\hline $\begin{array}{l}\text { HDL cholesterol } \\
{[\mathrm{mg} / \mathrm{dl}]}\end{array}$ & $\begin{array}{l}62(13) \\
{[34-91]}\end{array}$ & $\begin{array}{l}63(9) \\
{[42-78]}\end{array}$ & $\begin{array}{l}61(16) \\
{[34-91]}\end{array}$ & $\begin{array}{l}-1.79 \\
{[-9.28-5.70]}\end{array}$ & -0.48 & $p=0.63$ \\
\hline $\begin{array}{l}\text { triglyceride } \\
{[\mathrm{mg} / \mathrm{dl}]}\end{array}$ & $\begin{array}{l}87(55) \\
{[31-359]}\end{array}$ & $\begin{array}{l}84(43) \\
{[41-359]}\end{array}$ & $\begin{array}{l}90(66) \\
{[31-160]}\end{array}$ & $\begin{array}{l}5.78 \\
{[-26.30-37.85)}\end{array}$ & 0.36 & $p=0.72$ \\
\hline $\begin{array}{l}\text { fasting glucose } \\
{[\mathrm{mg} / \mathrm{dl}]}\end{array}$ & $\begin{array}{l}93(7) \\
{[73-107]}\end{array}$ & $\begin{array}{l}92(6) \\
{[73-102]}\end{array}$ & $\begin{array}{l}95(8) \\
{[79-107]}\end{array}$ & $\begin{array}{l}2.46 \\
{[-1.57-6.50]}\end{array}$ & 1.23 & $p=0.2258$ \\
\hline $\begin{array}{l}\text { high sensitive C-reactive protein } \\
{[\mathrm{mg} / \mathrm{dl}]}\end{array}$ & $\begin{array}{l}0.16(0.57) \\
{[0.01-4.02]}\end{array}$ & $\begin{array}{l}0.09(0.12) \\
{[0.01-0.46]}\end{array}$ & $\begin{array}{l}0.25(0.81) \\
{[0.01-4.02]}\end{array}$ & $\begin{array}{l}0.16 \\
{[-0.18-0.51]}\end{array}$ & 0.96 & $p=0.35$ \\
\hline PROCAM score [\%] & $\begin{array}{l}1.9(1.6) \\
{[0.39-8.47]}\end{array}$ & $\begin{array}{l}1.3(1.0) \\
{[0.39-5.01]}\end{array}$ & $\begin{array}{l}2.4(1.8) \\
{[0.46-8.47]}\end{array}$ & $\begin{array}{l}1.11 \\
{[0.24-1.97]}\end{array}$ & 2.60 & $p=0.01$ \\
\hline Relative PROCAM score [\%] & $\begin{array}{l}16.8(10.4) \\
{[5.5-44.3]}\end{array}$ & $\begin{array}{l}14.8(10.2) \\
{[6.0-44.3]}\end{array}$ & $\begin{array}{l}18.9(10.5) \\
{[5.5-44.3]}\end{array}$ & $\begin{array}{l}0.04 \\
{[-0.02-0.10]}\end{array}$ & 1.37 & $p=0.18$ \\
\hline
\end{tabular}

${ }^{1} \mathrm{Chi}^{2}$

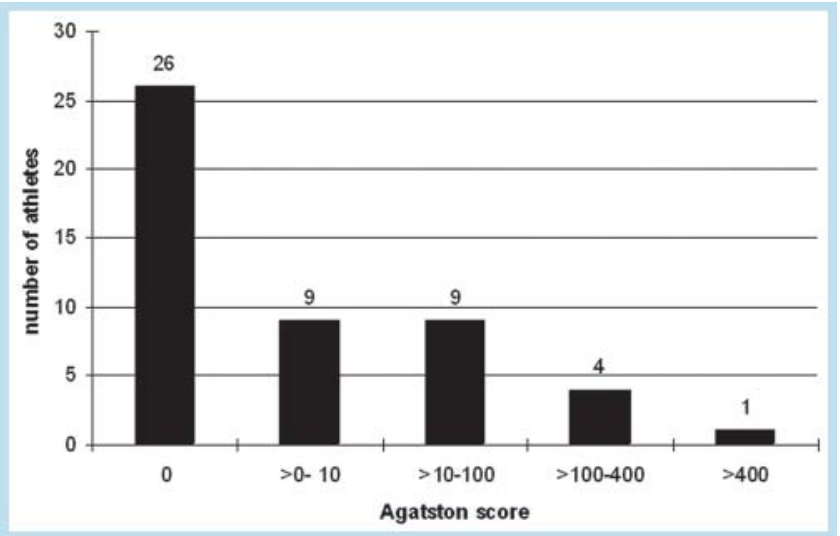

Fig. 1 Distribution of Agatston score within the study population.

Abb. 1 Verteilung des Agatston Score innerhalb der Studienpopulation. sis and percutaneous transluminal angioplasty and stent implantation were performed.

\section{Plaque location}

A total of 16 proximal plaques (segments 1,6 or 11 ) were detected ( 8 calcified plaques, 4 mixed plaques, 4 non-calcified plaques) in $12(24 \%)$ athletes. 4 participants had two proximal segments with atherosclerotic lesions. From the 4 proximal non-calcified plaques 2 were classified as moderate, the other 2 as mildly stenotic. $\triangle$ Fig. 5 shows a mixed plaque located in the proximal left anterior descending artery.

\section{Impact of traditional risk factors}

Besides age, systolic blood pressure and PROCAM score, only a family history of cardiovascular disease was associated with an increased risk for coronary atherosclerosis ( 0 Table 2). The distribution of former smoking, hypertension or hypercholesterolemia was not different between persons with or without coronary cal- 


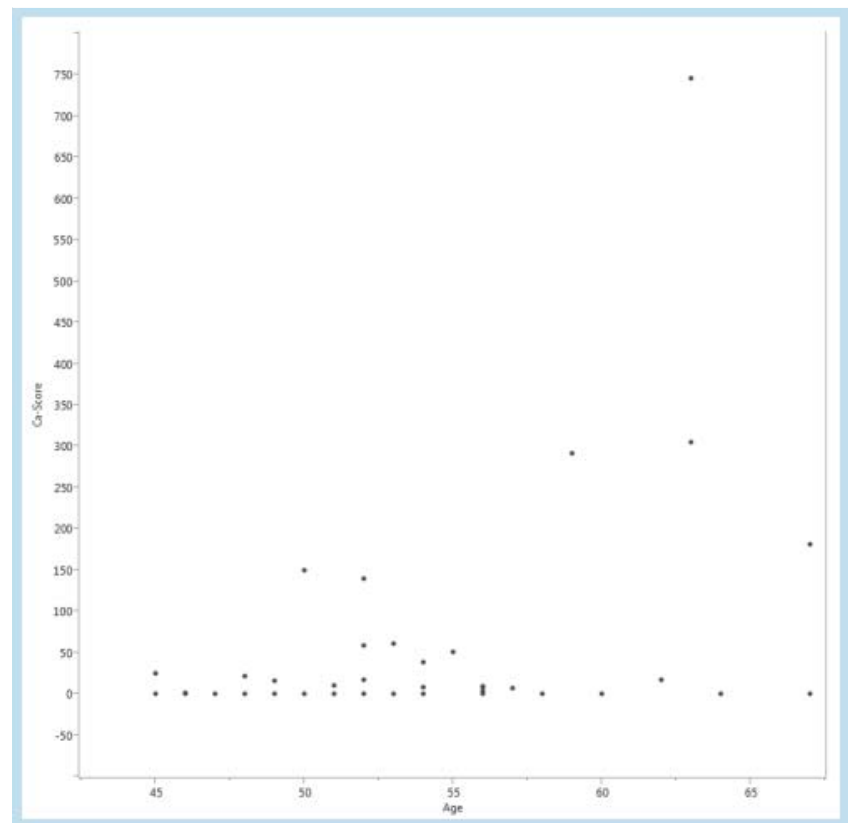

Fig. 2 Correlation between calcium score and age.

Abb. 2 Korrelation zwischen Calcium-Score und Alter.

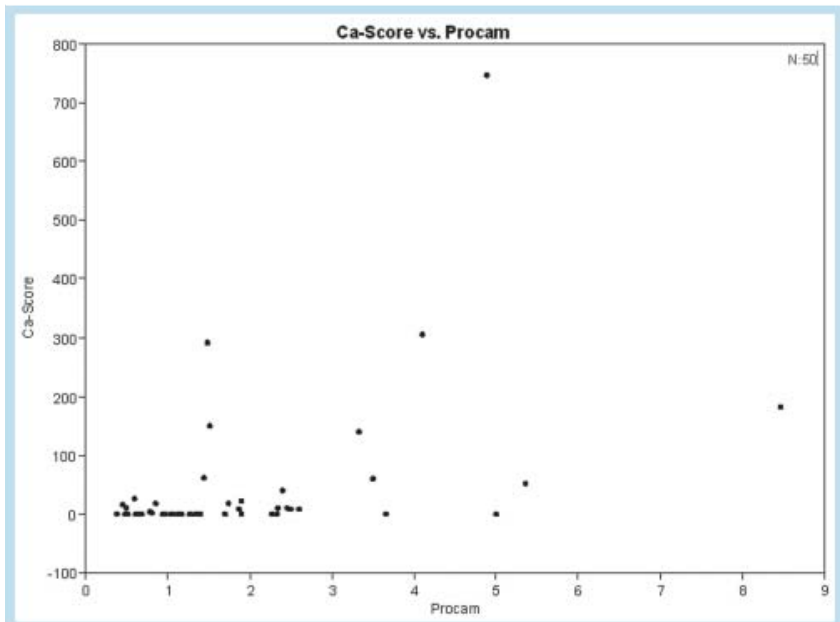

Fig. 3 Correlation between calcium score and PROCAM score.

Abb. 3 Korrelation zwischen Calcium-Score und PROCAM Score.

cifications or the four groups according to the degree of CAD (no vs. mild vs. moderate vs. significant CAD).

\section{Scan mode and radiation exposure}

Calcium scoring was performed using the high pitch mode in all participants. The mean effective radiation dose for calcium scoring was $0.30 \mathrm{mSv}$ (range $0.18-0.46$, SD 0.05 ). For CTA the high pitch mode was used in 21 (42\%) athletes, while the remaining athletes were scanned using the step-and-shot technique. The mean effective dose for CTA was $1.26 \mathrm{mSv}$ (range $0.64-2.74$, median 1.20 , SD 0.54). The effective dose was statistically significantly lower in persons scanned in high pitch mode ( 0.76 vs. $1.62 \mathrm{mSv}, \mathrm{p}<0.0001$ ).

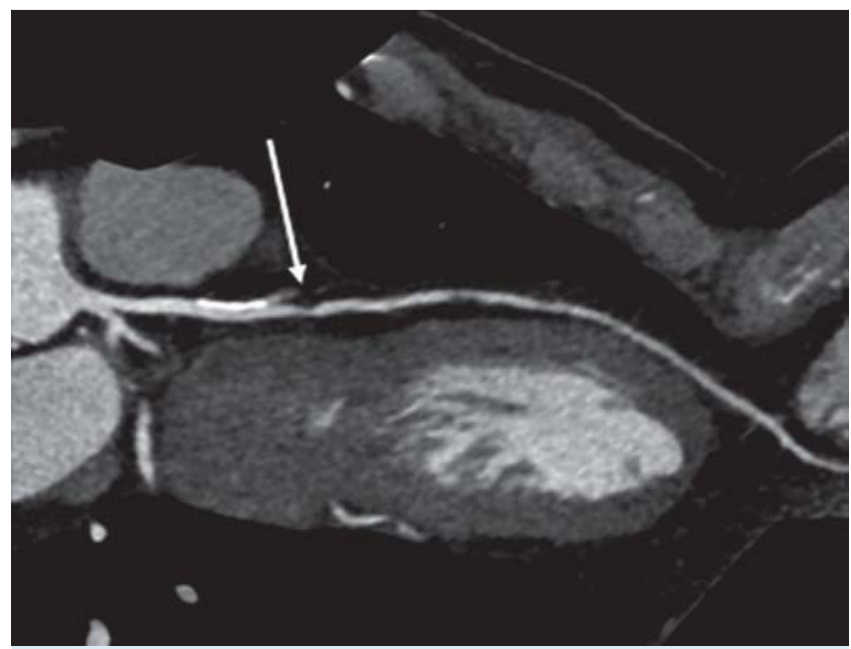

Fig. 4 Curved multiplanar reconstruction of the left anterior descending artery with high-grade stenosis (arrow).

Abb.4 Gekrümmte multiplanare Rekonstruktion des Ramus interventrikularis anterior mit einer hochgradigen Stenose (Pfeil).

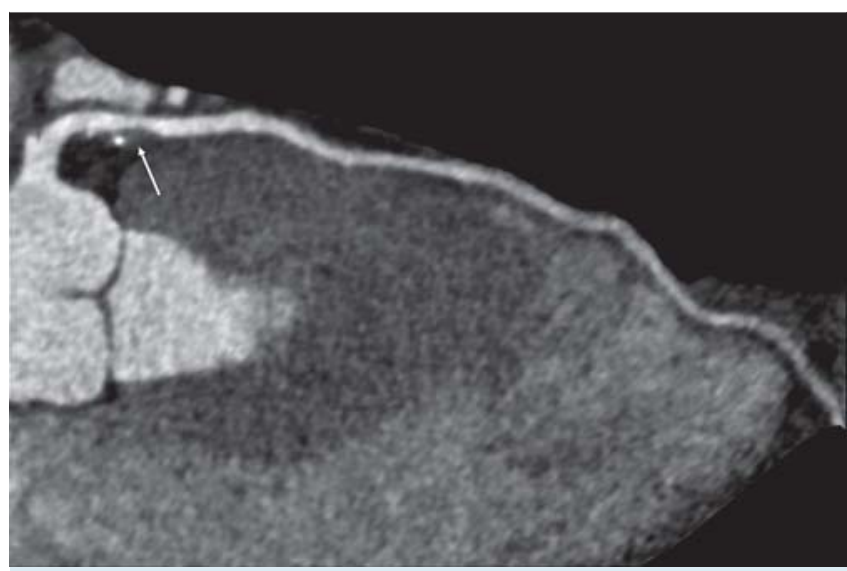

Fig. 5 Moderate stenosis of the proximal left anterior descending artery caused by mixed plaque formation. Curved multiplanar reconstruction.

Abb.5 Moderate Stenose des Ramus interventrikularis anterior durch eine gemischte Plaque (Pfeil). Gekrümmte multiplanare Rekonstruktion.

Table 2 Risk factors and their association between coronary calcification and the degree of coronary artery disease (CAD).

Tab. 2 Risikofaktoren und ihre Assoziation zwischen koronaren Kalzifikationen und dem Schweregrad der Koronaren Herzkrankheit (KHK).

\begin{tabular}{|llll|}
\hline risk factor & $\begin{array}{l}\text { coronary ather- } \\
\text { osclerosis } \\
\text { Pearson's Chi }\end{array}$ & $\begin{array}{l}\text { odds ratio } \\
{[95 \% \mathrm{Cl}]}\end{array}$ & $\begin{array}{l}\text { degree of CAD - } \\
\text { Pearson's Chi }\end{array}$ \\
\hline family risk & $\mathbf{0 . 0 0 1 9}$ & $\begin{array}{l}\mathbf{6 . 6 0} \\
{[1.92-\mathbf{2 2 . 6 2}]}\end{array}$ & $\mathbf{0 . 0 2}$ \\
\hline hypertension & 0.5713 & $\begin{array}{l}1.71 \\
{[0.26-11.26]}\end{array}$ & 0.55 \\
\hline former smoking & 0.2715 & $\begin{array}{l}1.94 \\
{[0.60-6.34]}\end{array}$ & 0.46 \\
\hline $\begin{array}{l}\text { hypercho- } \\
\text { lesterolemia }\end{array}$ & 0.0861 & - & 0.44 \\
\hline
\end{tabular}




\section{Discussion}

$\nabla$

According to our data, male marathon runners have a low risk of having obstructive coronary artery disease, as only one participant in our study had high-grade stenosis leading to revascularization.

On the other hand, coronary atherosclerosis was seen in almost $50 \%$ of our participants. This is of major importance, as a high percentage of coronary events is caused by non-obstructive coronary alterations [16]. Identifying individuals with coronary atherosclerosis (non-obstructive as well as obstructive) might therefore help to calculate the risk for cardiovascular events more precisely.

\section{Study population}

In contrast to other studies, athletes with only one finished marathon were not excluded. Thus, our results might be more transferable to real life as persons with no or minimal long-distance running experience constitute a relevant group of marathon participants today. Additionally, the participants were characterized very well in terms of their sports activity and cardiovascular fitness. Thus, the influence of training volume, training experience, number of completed marathons, VO2 max. or personal minimum time on our results could be evaluated.

\section{Traditional risk factors and PROCAM score}

Interestingly, beside age and a family history of cardiovascular disease, traditional cardiovascular risk factors did not differ between athletes with and without coronary artery disease. Both groups had very favorable cardiovascular risk profiles, which is underlined by a mean PROCAM score of only $1.9 \%$ with a maximum of $8.47 \%$. Compared to the PROCAM score of an age-matched group, the relative risk was only $16.8 \%$. The highest relative PROCAM score was $44.3 \%$. The observed difference between participants with and without coronary artery disease in terms of the PROCAM score might be driven by the fact that persons with coronary atherosclerosis were older. Probably some of the participants had a higher PROCAM score before starting regular physical activity which might explain at least in part the mismatch between PROCAM score and calcium score in some athletes ( $\bullet$ Fig. 3 ).

Although there was a significant difference in terms of systolic blood pressure between athletes with and without coronary calcifications, this observation has no clinical consequence as blood pressure might be subject to short-term changes, e.g. due to mental stress. Nevertheless, there could be other reasons for high blood pressure in these persons like unrecognized hypertension. Since we only had a measurement of blood pressure at one time point, further examination of these participants with e. g. 24h-blood pressure monitoring would be necessary for evaluating this fact.

On the other hand, a family history of cardiovascular disease was associated with an odds ratio of 6.6 for having coronary artery disease. As a consequence, more detailed risk stratification in athletes with a family history of cardiovascular disease should be taken into account.

\section{Coronary artery disease in marathon runners}

The association between premature coronary artery disease and marathon running is discussed controversially. Large prospective epidemiologic studies have shown reduced rates of coronary heart disease with regular exercise [1, 17]. However, in their study including 108 marathon runners, Mohlenkamp et al. re- ported higher calcium scores in athletes compared to age- and risk-factor-matched controls. This observation is of major importance as coronary calcification is an independent risk factor for all-cause mortality and cardiovascular events [18].

In contrast to the study published by Mohlenkamp, the median CS in our cohort was lower (0 vs. 36 ) which might be explained by different factors: Firstly, our collective was younger (53 years vs. 57 years). Secondly, lipid values (104 vs. $121 \mathrm{mg} / \mathrm{dL}$ ) and the percentage of ex-smokers (34\% vs. $51.9 \%$ ) were lower. And thirdly, our marathon runners were probably fitter with a median personal minimum time of less than 3:30 h. Taken together, the comparison between the two studies is doubtful.

Data about contrast-enhanced CTA are rare. Just recently a paper from Karlstedt et al. reported about CTA results in 25 marathon runners (21 male, mean age 55 years) [19]. Coronary atherosclerosis was only detected in 2 athletes. However, the low prevalence of CAD might be explained by the very strict exclusion criteria as athletes with a history of smoking, hypertension, hypercholesterolemia or diabetes were not enrolled. Additionally, data about coronary calcium score are missing.

\section{Prognostic value of CTA}

The prognostic value of CTA in persons without known CAD has been demonstrated in a cohort of more than 24000 individuals [20] although screening examinations with CTA are not recommended [13]. According to the CONFIRM registry, the absence of CAD is associated with an excellent outcome, whereas the risk for death increases by the extent of CAD. These data were confirmed by a study from Hou et al. [21]. In 5007 persons they were able to demonstrate that CTA was superior to CS in terms of predicting cardiovascular events. Remarkably, not only the extent of CAD but also the plaque characteristics were predictive for major events with an unfavorable outcome for mixed plaques. Newest data from the CONFIRM registry showed that mixed or calcified plaques in the proximal coronary system or a proximal stenosis of more than $50 \%$ is equivalent to an increase in age of 5 years or the risk caused by smoking [22]. Applying this system, 10 (20\%) of our athletes fulfil one of these criteria and might be at higher risk than expected by traditional risk markers.

However, as recently shown, the prognosis of persons with a comparable extent of disease - as assessed by CTA - depends on additional parameters like diabetes mellitus [23]. Thus, marathon runners might have a favorable prognosis compared to sedentary persons with a similar coronary status. The prognostic value of our data will be evaluated during a five-year follow-up period and thus remains unclear at present. Nevertheless, all athletes with coronary artery disease were advised to take ASA. Although there is no evidence of such an approach reducing the cardiovascular risk, vigorous exercise is associated with a transient higher risk for acute coronary events [24].

\section{Limitations}

Our study had limitations. First, the number of participants was quite low. Additionally we only enrolled male marathon runners. This was driven by two considerations: Firstly, the risk to suffer from sudden cardiac death due to coronary artery disease is lower in women [25], and secondly radiation exposure applied for chest CT is higher in female persons [26]. Furthermore, the study protocol did not provide for scanning a control group due to ethical reasons. 


\section{Conclusion}

In conclusion, we could demonstrate that the prevalence of highgrade coronary stenosis in asymptomatic male marathon runners is low. However, almost $50 \%$ of our study population had coronary atherosclerosis despite a very favorable cardiovascular risk profile. A proximal plaque location was found in $24 \%$ of our marathon runners. Thus, standard risk factors as well as the PROCAM score obviously underestimate the cardiovascular risk of male marathon runners, which must be however evaluated by outcome studies. Cardiac CT might help to determine the cardiovascular risk in marathon runners although a routine examination cannot be recommended at present.

\section{Clinical relevance}

- Coronary atherosclerosis can be detected in almost $50 \%$ of male marathon runners aged older than 45 years.

- Only a minority of these persons have obstructive CAD. Treadmill exercise testing failed to detect these persons.

- Cardiac computed tomography might help to identify athletes with an elevated risk for coronary events, especially in persons with a family history of coronary artery disease.

$\begin{array}{ll}\text { Abbreviations } \\ \text { CAD } & \text { Coronary artery disease } \\ \text { CTA } & \text { CT angiography } \\ \text { CS } & \text { Calcium scoring } \\ \text { SD } & \text { Standard deviation }\end{array}$

\section{Acknowledgements}

This study was supported in part by a grant of Bayer Healthcare and of the "Karl und Lore Klein Stiftung".

\section{References}

1 Fletcher GF, Balady G, Blair SN et al. Statement on exercise: benefits and recommendations for physical activity programs for all Americans. A statement for health professionals by the Committee on Exercise and Cardiac Rehabilitation of the Council on Clinical Cardiology, American Heart Association. Circulation 1996; 94: 857-862

2 Corrado D, Schmied C, Basso C et al. Risk of sports: do we need a preparticipation screening for competitive and leisure athletes? Eur Heart J 2011; 32: 934-944

3 Maron BJ, Thompson PD, Ackerman MJ et al. Recommendations and considerations related to preparticipation screening for cardiovascular abnormalities in competitive athletes: 2007 update: a scientific statement from the American Heart Association Council on Nutrition, Physical Activity, and Metabolism: endorsed by the American College of Cardiology Foundation. Circulation 2007; 115: 1643-1455

4 Corrado D, Pelliccia A, Bjornstad HH et al. Cardiovascular pre-participation screening of young competitive athletes for prevention of sudden death: proposal for a common European protocol. Consensus Statement of the Study Group of Sport Cardiology of the Working Group of Cardiac Rehabilitation and Exercise Physiology and the Working Group of Myocardial and Pericardial Diseases of the European Society of Cardiology. Eur Heart J 2005; 26: 516 - 524

5 Borjesson M, Urhausen A, Kouidi E et al. Cardiovascular evaluation of middle-aged/ senior individuals engaged in leisure-time sport activities: position stand from the sections of exercise physiology and sports cardiology of the European Association of Cardiovascular Prevention and Rehabilitation. Eur J Cardiovasc Prev Rehabil 2011; 18: $446-458$
6 Maron BJ, Shirani J, Poliac LC et al. Sudden death in young competitive athletes. Clinical, demographic, and pathological profiles. JAMA 1996; 276: $199-204$

7 Corrado D, Drezner J, Basso C et al. Strategies for the prevention of sudden cardiac death during sports. Eur J Cardiovasc Prev Rehabil 2011; 18: $197-208$

8 Lloyd-Jones D, Adams RJ, Brown TM et al. Heart disease and stroke statistics - 2010 update: a report from the American Heart Association. Circulation 2010; 121: e46-e215

9 Rosamond W, Flegal K, Furie K et al. Heart disease and stroke statistics2008 update: a report from the American Heart Association Statistics Committee and Stroke Statistics Subcommittee. Circulation 2008; 117: e25-e146

10 Siscovick DS, Ekelund LG, Johnson JL et al. Sensitivity of exercise electrocardiography for acute cardiac events during moderate and strenuous physical activity. The Lipid Research Clinics Coronary Primary Prevention Trial. Arch Intern Med 1991; 151: 325 - 330

11 Diamond GA, Forrester JS. Analysis of probability as an aid in the clinical diagnosis of coronary-artery disease. N Engl J Med 1979; 300 (24): $1350-1358$

12 Schroeder S, Achenbach S, Bengel F et al. Cardiac computed tomography: indications, applications, limitations, and training requirements: report of a Writing Group deployed by the Working Group Nuclear Cardiology and Cardiac CT of the European Society of Cardiology and the European Council of Nuclear Cardiology. Eur Heart J 2008; 29: 531 556

13 Achenbach S, Barkhausen J, Beer M et al. Consensus recommendations of the German Radiology Society (DRG), the German Cardiac Society (DGK) and the German Society for Pediatric Cardiology (DGPK) on the use of cardiac imaging with computed tomography and magnetic resonance imaging. Fortschr Röntgenstr 2012; 184: 345-368

14 Assmann G, Cullen P, Schulte H. Simple scoring scheme for calculating the risk of acute coronary events based on the 10-year follow-up of the prospective cardiovascular Munster (PROCAM) study. Circulation 2002; 105: $310-315$

15 Rumberger JA, Brundage BH, Rader DJ et al. Electron beam computed tomographic coronary calcium scanning: a review and guidelines for use in asymptomatic persons. Mayo Clin Proc 1999; 74: 243-252

16 Libby $P$. Mechanisms of acute coronary syndromes and their implications for therapy. N Engl J Med 2013; 368: 2004-2013

17 Thompson PD, Buchner D, Pina IL et al. Exercise and physical activity in the prevention and treatment of atherosclerotic cardiovascular disease: a statement from the Council on Clinical Cardiology (Subcommittee on Exercise, Rehabilitation, and Prevention) and the Council on Nutrition, Physical Activity, and Metabolism (Subcommittee on Physical Activity). Circulation 2003; 107 (24): 3109-3116

18 Nucifora G, Bax JJ, van Werkhoven JM et al. Coronary artery calcium scoring in cardiovascular risk assessment. Cardiovasc Ther 2011; 29: e43-e53

19 Karlstedt E, Chelvanathan A, Da Silva $M$ et al. The impact of repeated marathon running on cardiovascular function in the aging population. J Cardiovasc Magn Reson 2012; 14: 58

20 Min JK, Dunning A, Lin FY et al. Age- and sex-related differences in allcause mortality risk based on coronary computed tomography angiography findings results from the International Multicenter CONFIRM (Coronary CT Angiography Evaluation for Clinical Outcomes: An International Multicenter Registry) of 23854 patients without known coronary artery disease. J Am Coll Cardiol 2011; 58: 849-860

21 Hou ZH, Lu B, Gao Y et al. Prognostic value of coronary CT angiography and calcium score for major adverse cardiac events in outpatients. JACC Cardiovasc Imaging 2012; 5: 990-999

22 Hadamitzky M, Achenbach S, Al-Mallah $M$ et al. Optimized prognostic score for coronary computed tomographic angiography: results from the CONFIRM registry (COronary CT Angiography EvaluatioN For Clinical Outcomes: An InteRnational Multicenter Registry). J Am Coll Cardiol 2013; 62: $468-476$

23 Rana JS, Dunning A, Achenbach S et al. Differences in prevalence, extent severity, and prognosis of coronary artery disease among patients with and without diabetes undergoing coronary computed tomography angiography: results from 10,110 individuals from the CONFIRM (COronary CT Angiography EvaluatioN For Clinical Outcomes): an InteRnational Multicenter Registry. Diabetes Care 2012; 35: 1787-1794 
24 Siscovick DS, Weiss NS, Fletcher RH et al. The incidence of primary cardiac arrest during vigorous exercise. N Engl J Med 1984; 311: 874 - 877

25 Roberts WO, Roberts DM, Lunos S. Marathon related cardiac arrest risk differences in men and women. Br J Sports Med 2013; 47: 168-171
26 Ketelsen D, Fenchel M, Thomas $C$ et al. Estimation of radiation exposure of retrospective gated and prospective triggered 128-slice triple-ruleout CT angiography. Acta Radiol 2011; 52: 762 - 766 